\title{
Evaluation of Stress Distribution in Implants Used to Retain Auricular Prosthesis with V-shaped and Reverse Buttress Thread Design by Three-dimensional Finite Element Analysis
}

\author{
Subramaniam Sripriya ${ }^{1}$, Ramkumar Karthikeyan ${ }^{2}$, Akshyallingam Meenakshi ${ }^{3}$, Chitha PP Sabarigirinathan $^{4}$
}

\begin{abstract}
Aim: To compare the stress distribution in the implant used to retain auricular prosthesis with V-shaped thread and reverse buttress thread design.

Materials and methods: Commercially available implant marketed by southern implant with V-shaped thread was taken as the control group. This parameter was taken to manufacture indigenous implant with reverse buttress thread design. Both the indigenous implant and commercially implant were scanned by noncontact profilometer using optical comparator (Deltronics Corp, USA). These data were imported into Pro/E wildfire 4.0 software (PTC, USA) for the creation of a three-dimensional (3D) model. Human skull was scanned using the 3D white light scanner, and these data were converted into surface model with the help of computer-aided design and drafting (CAD)/computer-aided manufacturing

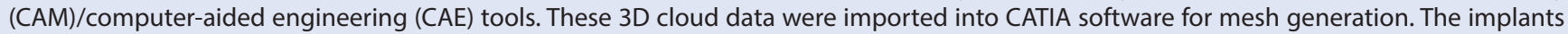
were placed in the specified location in the temporal bone. The next step was loading on the implant $10 \mathrm{~N}$ axial loading on the center of the implant and moment on the same area of $100 \mathrm{~N} \mathrm{~mm}$ was done. The effect of load distribution with and without bar connection was assessed. Results: The statistical significance of the data within the group was assessed using mean and standard deviation and that between the group was assessed using Levene's test for variance and $t$ test for mean. The stress distribution is more at the flange and less at the end and considerably reduced on connection with bar.

Conclusion: The presence of the flange in the craniofacial implant decides the stress distribution and is not by the shape of the thread.

Keywords: Auricular prosthesis, Craniofacial implant, Finite element analysis, Implants for auricular prosthesis.

International Journal of Prosthodontics and Restorative Dentistry (2020): 10.5005/jp-journals-10019-1264
\end{abstract}

\section{INTRODUCTION}

The success of implantology depends on various factors such as biomechanics, loading protocol, implant design, and finally the most important is the prosthesis design which influence the biomechanics of the implant. Biomechanics is one of the most important factor for the long-term stability of an osseointegrated implant, because mechanical stress by functional loading inevitably influences long-term peri-implant bone remodeling (Alberktsson 1983; Hoshaw, Brunski and Cochran 1994). Implants are widely used in the rehabilitation of intraoral defects and also used in the restoration of extraoral defects.

In 1975, Branenmark postulated that a skin-penetrating implant should be possible based on the principles of dental implants. ${ }^{2}$ In 1979, implants were placed in the mastoid bone to retain an ear prosthesis, this pioneering work was done in Gothenburg University, Sweden, ${ }^{2}$ and after this implants were widely used as treatment option to retain the maxillofacial prosthesis.

Craniofacial implant differs from that of the oral implant in two aspects, namely, the length is less in the range of 3-4 mm and with a flange that prevents the accidental perforation of the implant through the thin bone sites, which are encountered in the craniofacial anatomy. ${ }^{3}$ Buttress thread forms are considered more suited for supporting facial prosthesis. ${ }^{4}$

Evidence of scientific literature on finite element analysis (FEA) are available for the intraoral implants, but it cannot be applied to the extraoral situation because of the variation in the following aspects: environment, microflora, skin, reduced bone volume
1,3,4 Department of Prosthodontics, Tamilnadu Government Dental College and Hospital, Chennai, Tamil Nadu, India

${ }^{2}$ Department of Dental Surgery, Stanley Medical College, Chennai, Tamil Nadu, India

Corresponding Author: Ramkumar Karthikeyan, Department of Dental Surgery, Stanley Medical College, Chennai, Tamil Nadu, India, Phone: +91 44 25281348, e-mail: ram.kamala@gmail.com

How to cite this article: Sripriya S, Karthikeyan R, Meenakshi A, et al. Evaluation of Stress Distribution in Implants Used to Retain Auricular Prosthesis with V-shaped and Reverse Buttress Thread Design by Three-dimensional Finite Element Analysis. Int J Prosthodont Restor Dent 2020;10(2):62-71.

Source of support: Nil

Conflict of interest: None

demanding shorter implant, and reduced load. ${ }^{5}$ The FEA studies on the craniofacial implants used to retain auricular prosthesis are very few and most of them were $2 \mathrm{D}$ FEA; hence, a study with $3 \mathrm{D}$ FEA was planned with the following aims and objectives.

The aim of this study was to compare the biomechanical aspect of commercially available implant with V-shaped thread and indigenously developed craniofacial implant with reverse buttressshaped thread used to retain auricular prosthesis by using FEA. The objectives of the study are (1) stress distribution on the implant and the temporal bone are assessed by keeping the diameter constant and varying the length of craniofacial implant with V-shaped and

(-) The Author(s). 2020 Open Access This article is distributed under the terms of the Creative Commons Attribution 4.0 International License (https://creativecommons. org/licenses/by-nc/4.0/), which permits unrestricted use, distribution, and non-commercial reproduction in any medium, provided you give appropriate credit to the original author(s) and the source, provide a link to the Creative Commons license, and indicate if changes were made. The Creative Commons Public Domain Dedication waiver (http://creativecommons.org/publicdomain/zero/1.0/) applies to the data made available in this article, unless otherwise stated. 
reverse buttress-shaped thread design in commercially available and indigenously developed implant, respectively, (2) the stress distribution to the surrounding temporal bone was assessed after connecting the two implants with a bar.

\section{Materials and Methods}

\section{Grouping of Samples}

The samples were arranged into groups I, II (Table 1) III, and IV (Table 2). Table 1 shows the details of the implant used without the connection bar. Group I consists of commercially available implant with V-shaped thread and a diameter of $3.75 \mathrm{~mm}$. Group I consists of subgroups of IA, IB, and IC where the diameter of the implant is kept constant at $3.75 \mathrm{~mm}$ and the varying lengths of 3, 4, and $6 \mathrm{~mm}$, respectively. Group II consists of an indigenous implant with buttress thread design of $3.75 \mathrm{~mm}$ diameter and the varying lengths of 3,4 , and $6 \mathrm{~mm}$ designated as IIA, IIB, and IIC. The implants of groups I and II were connected with bar in groups III and IV. The entire details are shown in Tables 1 and 2 .

The materials and method is divided into following steps:

Step I: Procurement of commercially available craniofacial implant used to retain auricular prosthesis.

Step II: Fabrication of indigenous implant used to retain auricular prosthesis.

Step III: Generation of finite element models and placing implant in the specified location

Step IV: Generation of finite element model with two implants in position and connected by a gold bar.

Step V: Assignment of material properties to the FEA model

Step VI: Loading (steps III to VI was done at the Central Institute of Plastic and Engineering Technology, Guindy, Chennai).

\section{Step I: Procurement of Craniofacial Implant}

The conventional craniofacial implant is an auricular implant marketed by the Southern Implant, South Africa, is selected as the control group. These implants are machined from unalloyed titanium. For surgical implant application grade IV titanium was used. ${ }^{6}$ The thread design present in this implant is V-shaped. The size of the implant is $3.75 \mathrm{~mm}$ diameter and $3 \mathrm{~mm}$ length (Fig. 1).

\section{Step II: Fabrication of Indigenous Implant}

The procured craniofacial implant was drawn on the computer using CAD 2004 software with V-shaped thread design, and keeping this as a prototype another diagram was drawn with

Table 1: Grouping of samples: implants without bar connection reverse buttress thread design. Data of the drawing drawn was fed into the computerized numerical control (CNC) milling machine Lokesh (CNC Machine, Hyderabad). Grade II titanium was procured from Madhani, Labs, Hyderabad, were fed into the machine and milling was done. The steps involved in making the root form of the implant are root feeding, step turning, threading, and parting. The antirotational component was made in vertical machining center. The steps involved are centering, drilling, and tapping. The indigenous implant developed is shown in Figure 2.

\section{Step III: Generation of Finite Element Models}

It will be discussed under the following headings

- Generation of finite element model of implant

- Generation of finite element model of the temporal bone

- Placing the implant in the specified location.

\section{Step III-1: Generation of Finite Element of the Model of the Implant}

The commercially available and indigenously developed craniofacial implant was scanned by noncontact profilometer using an optical comparator (Deltronics Corp, USA) (Fig. 3). A vertical resolution was measured at the nanometer level, and it gives 1,000 time projection. The dimension of the thread in the commercially available implant with V-shaped thread is $60^{\circ}$ and $47^{\circ}$ in indigenously developed

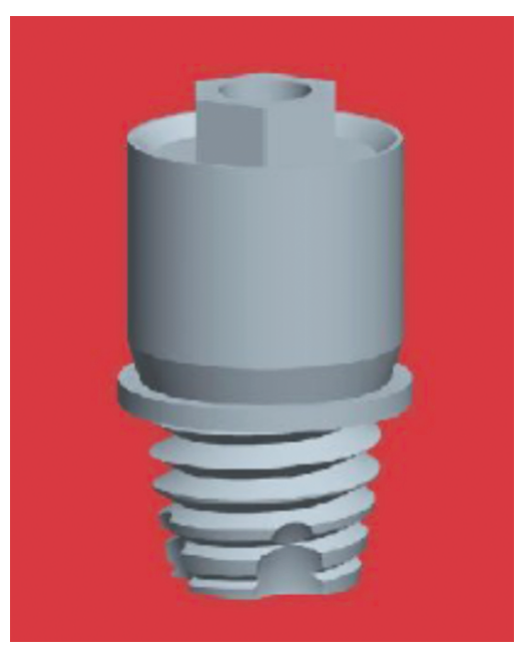

Fig. 1: Commercially available craniofacial implant

\begin{tabular}{ll}
\hline Group I-Commercially available implant with V-shaped thread & Group II-Indigenous implant with Buttress-shaped thread \\
\hline Group IA-3.75 $\mathrm{mm}$ dia and $3 \mathrm{~mm}$ length & Group IIA-3.75 $\mathrm{mm}$ dia and $3 \mathrm{~mm}$ length \\
Group IB-3.75 $\mathrm{mm}$ dia and $4 \mathrm{~mm}$ length & Group IIB-3.75 $\mathrm{mm}$ dia and $4 \mathrm{~mm}$ length \\
Group IC-3.75 $\mathrm{mm}$ dia and $6 \mathrm{~mm}$ length & Group IIC-3.75 $\mathrm{mm}$ dia and $6 \mathrm{~mm}$ length \\
\hline
\end{tabular}

Table 2: Grouping of samples: implants with bar connection

\begin{tabular}{ll}
\hline Group III-Commercially available implant with V-shaped thread & Group IV-Indigenous implant with buttress-shaped thread \\
\hline $\begin{array}{l}\text { Group IIIA-Two implants of } 3.75 \mathrm{~mm} \text { dia and } 3 \mathrm{~mm} \text { length; one at } \\
\text { the cranial and the other at the caudal location }\end{array}$ & $\begin{array}{l}\text { Group IVA-Two implants of } 3.75 \mathrm{~mm} \text { dia and } 3 \mathrm{~mm} \text { length; one at the } \\
\text { cranial and the other at the caudal location }\end{array}$ \\
$\begin{array}{l}\text { Group IIIB-Two implants of } 3.75 \mathrm{~mm} \text { dia and } 4 \mathrm{~mm} \text { length; one at } \\
\text { the cranial and the other at the caudal location }\end{array}$ & $\begin{array}{l}\text { Group IVB-Two implants of } 3.75 \mathrm{~mm} \text { dia and } 4 \mathrm{~mm} \text { length; one at the } \\
\text { cranial and the other at the caudal location }\end{array}$ \\
$\begin{array}{l}\text { Group IIIC-Two implants of } 3.75 \mathrm{~mm} \text { dia and } 6 \mathrm{~mm} \text { length; one at } \\
\text { the cranial and the other at the caudal location }\end{array}$ & $\begin{array}{l}\text { Group IVC-Two implants of } 3.75 \mathrm{~mm} \text { dia and } 6 \mathrm{~mm} \text { length; one at the } \\
\text { cranial and the other at the caudal location }\end{array}$ \\
\hline
\end{tabular}




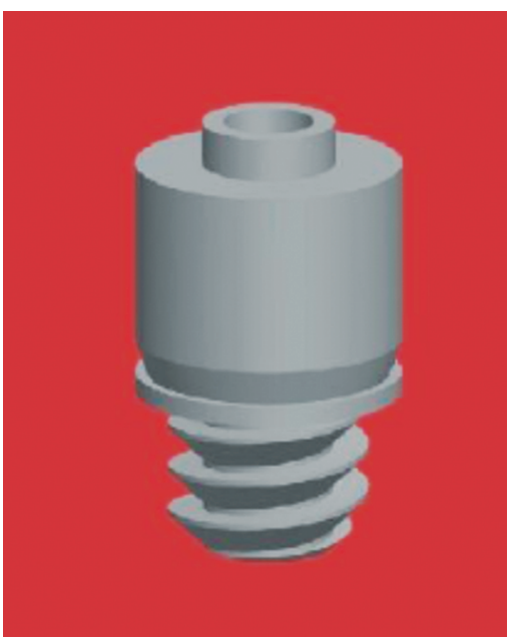

Fig. 2: Indigenously made craniofacial implant

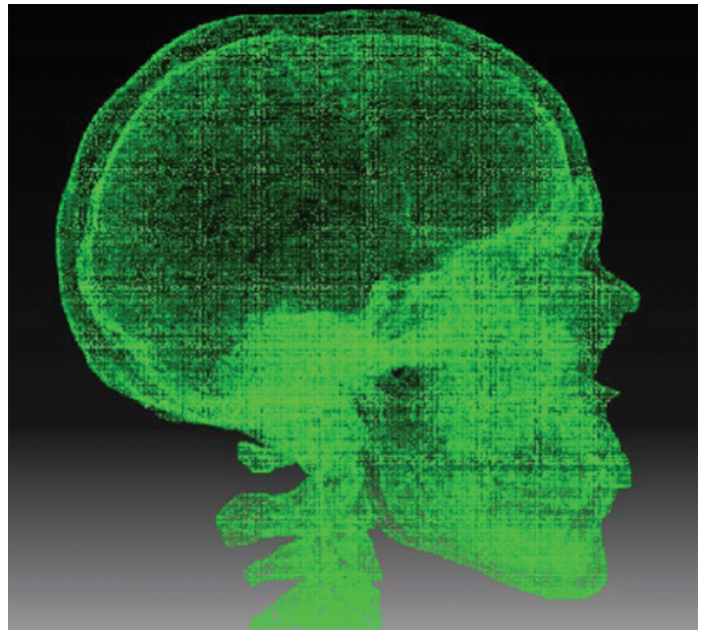

Fig. 4: 3D cloud generation of skull by using 3D white light scanner

implant with reverse buttress thread. These data were imported in to Pro/E wildfire 4.0 software (PTC, USA) for the creation of 3D model. This model was imported to the ANSYS work bench 11.0 (ANSYS Inc,USA) software through initial graphic exchange specification for meshing and analyzing the implant. The implants were created by keeping the diameter $3.75 \mathrm{~mm}$ constant and varying the length to 3 , 4 , and $6 \mathrm{~mm}$ with $V$-shaped thread implant ( 3 numbers) and buttressshaped thread implant ( 3 numbers). In total six implants were created virtually to analyze the biomechanical load distribution.

\section{Step III-2: Generation of Finite Element Model of Temporal Bone}

This step discusses about the generation of finite model of temporal bone. Human skull with mandible and full set of teeth was scanned through 3D white light scanner. Using fiber white light and different size of fringe pattern, the 3D cloud data of the skull was captured. The area of interest, i.e., the temporal bone texture was assessed with thousand point in $1 \mathrm{~cm}$ area. The file was saved in ASCII format for future development, and the scanned image is shown in Figure 4. The point cloud data obtained from $3 \mathrm{D}$ white light scanner is converted into surface model with the help of computer aided design and drafting (CAD)/computer aided manufacturing (CAM)/computer aided engineering (CAE) tools.

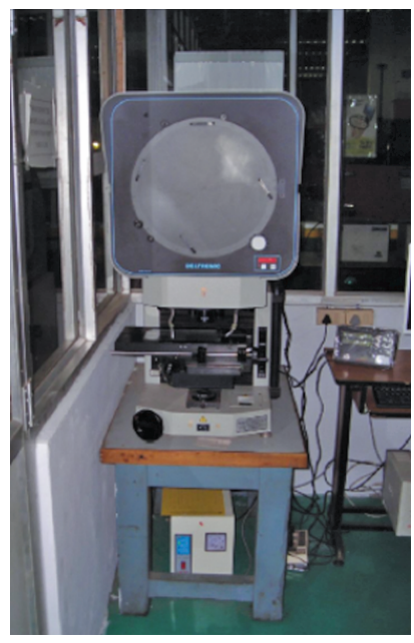

Fig. 3: Noncontact profilometer

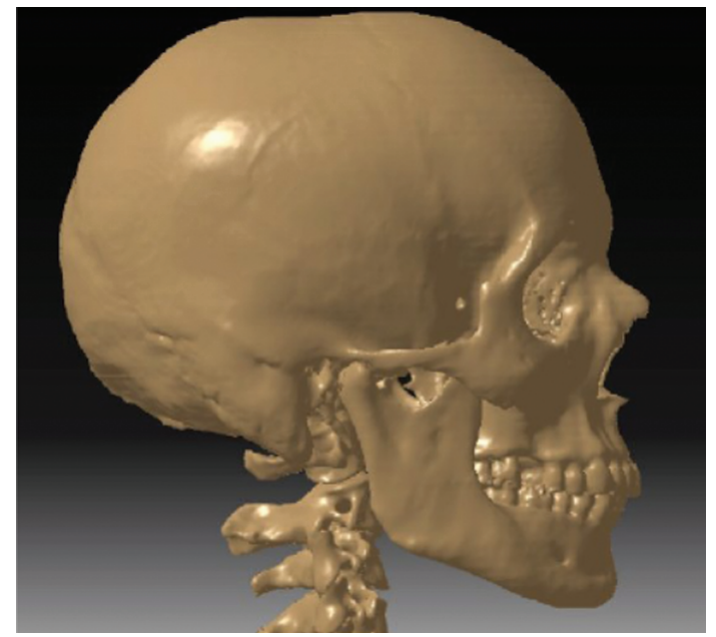

Fig. 5: Mesh generation from 3D cloud data using CATIA software

The 3D cloud data were imported into CATIA software for mesh generation. Each mesh shape was generated through 3 points to form a triangle called the facet body, and the mesh model is shown in Figure 5 . The mesh model does not have the surface detail; moreover, it is hollow in nature. CATIA software creates the surface details and converts the model into a solid one as is shown in Figure 6.

\section{Step III-3: Locating the Sites for Placing the Implant}

The next step is locating the ideal site for placement of the implant. According to the literature, the ideal placement is $18-20 \mathrm{~mm}$ from the center of the external ear canal opening. On the left-hand side between 1 and 2 O'clock position for the most cranial implant and between 3.30 and 4.30 position for the caudal implant. The ideal placement on the right-hand side is between 10 and 11 O'clock position for the most cranial part and between the 7 and $80^{\prime}$ 'clock positions for the caudal implant, ${ }^{7}$ and it was located on the model by using the CATIA software as shown in Figure 7. Tetrahedral type of element was selected, and the size of the element was $0.1 \mathrm{~mm}$. The models consisted of 59,345 elements and 101,590 nodes as shown in Figure 8. When loading the bone, there should not be any movement, and hence the internal surface was given a fixed support as shown in Figure 9. 


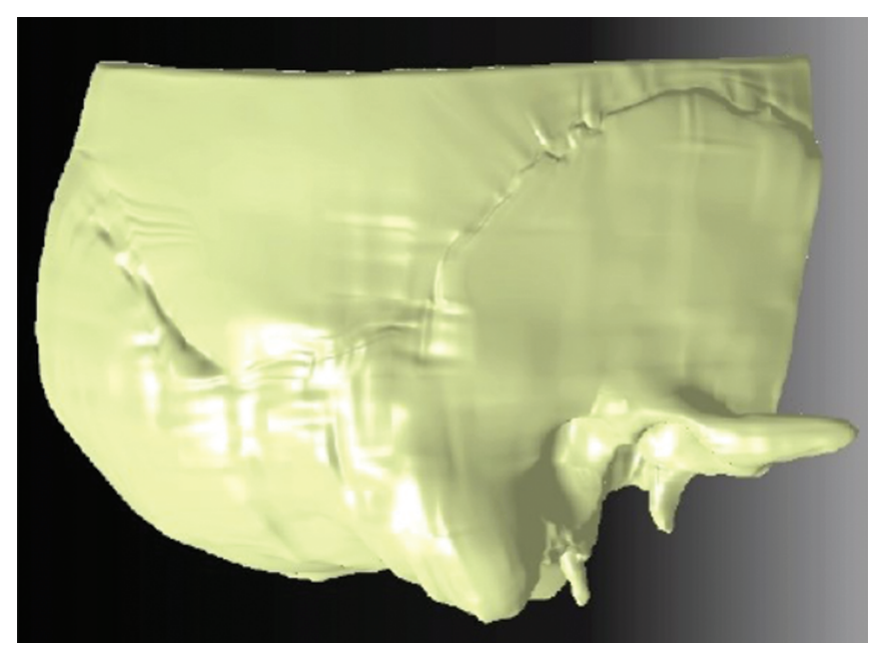

Fig. 6: Surface and solid generation of temporal bone using CATIA software

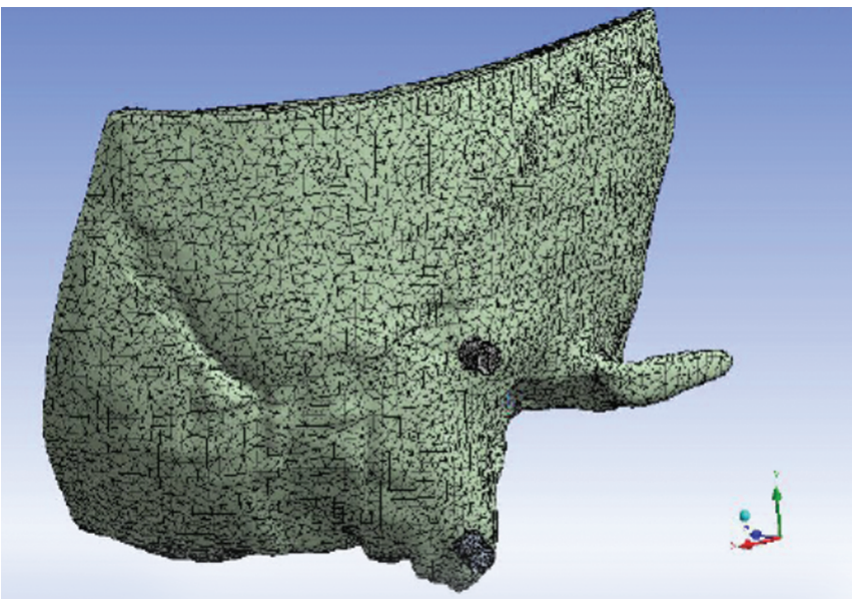

Fig. 8: Finite element model of temporal bone showing nodes and elements

\section{Step IV: Generation of Finite Element Model with Two Implants in Position and Connected by Gold Bar}

In total, six FEA models with two implants of V-and buttress-shaped thread design in each model with a constant diameter of $3.75 \mathrm{~mm}$ and length $3 \mathrm{~mm}, 4 \mathrm{~mm}$, and $6 \mathrm{~mm}$ were placed in the temporal as discussed above. All the above six models were again connected by bar and loaded to analyze the stress distribution (Fig. 10). In all, 12 models (6 without bar and 6 with bar) were generated for the analysis.

\section{Step V: Assignment of Material Properties to the FEA Model}

The assignment of material properties to a finite element model is a necessary step. The stress-strain relationship in a structure was based on the material properties. These are Young's modulus (modulus of elasticity) and Poisson's ratio. Material properties in the dental FEA are mostly modeled as isotropic and homogenous. The implant model used in this study is commonly available. Titanium with elastic modulus $(e)=1.03 \times$ $105 \mathrm{MPa}$, Poisson's ratio $(u)=0.35$, and density of implant $4.5 \mathrm{~g} /$ $\mathrm{cm}^{3}$ were assigned as the property for the craniofacial implant. The entire volume of the temporal bone was considered to be a homogeneous, isotropic material with the character of [elastic

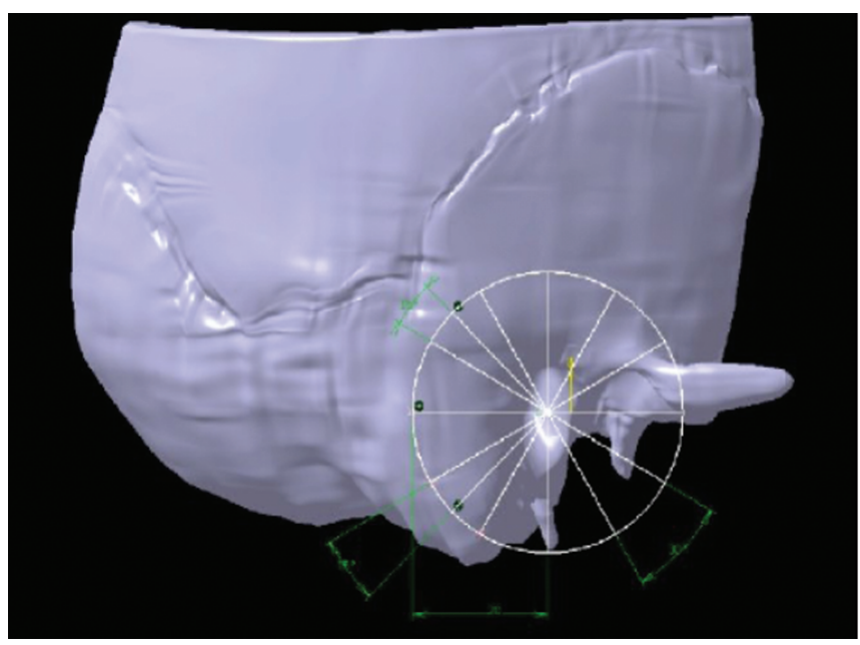

Fig. 7: Location for placing the implant in the temporal bone using CATIA software

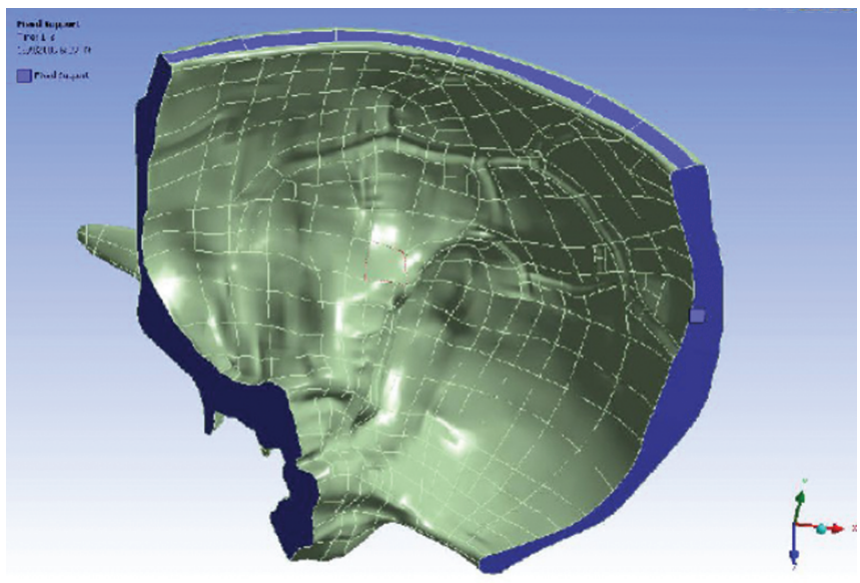

Fig. 9: Nodes and elements over the internal surface with fixed support for analysis

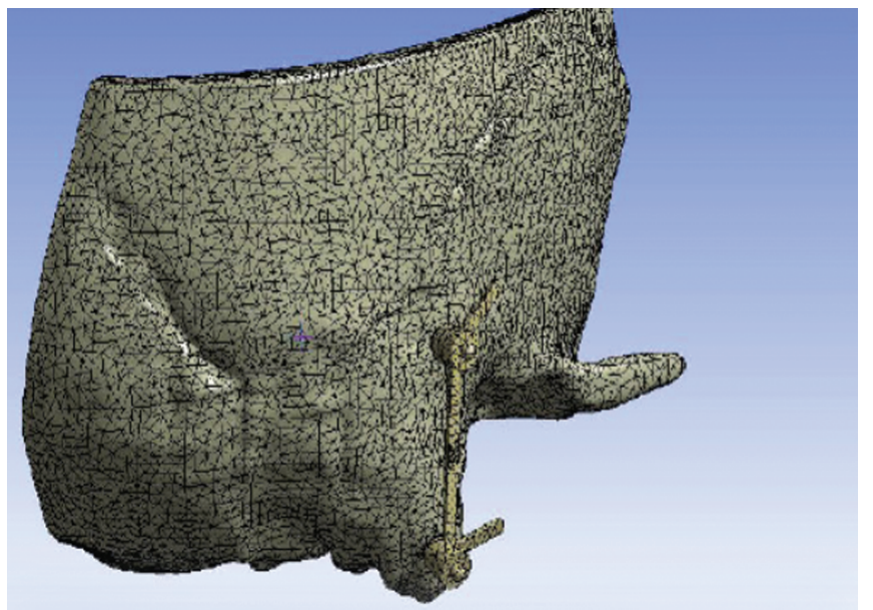

Fig. 10: Finite element model of craniofacial implant with gold alloy casting bar containing nodes and elements using ANSYS software

modulus (e) 14,000 MPa, Poisson's ratio $(u)=0.3]$. The interface between the implant and the temporal bone was assumed to be an immovable junction. For this a "fixed contact" option in the software was chosen. 


\section{Step VI: Loading}

The next step involves $10 \mathrm{~N}$ axial loading on the center of the implant and $100 \mathrm{~N} \mathrm{~mm}$ moment on the same area was done. The load applied to the craniofacial auricular implant was the static type loading. A force of $10 \mathrm{~N}$ axial loading on the center of gold bar connecting two implant and a moment of $100 \mathrm{~N}$ were also analyzed with the static type of loading, ${ }^{8}$ as shown in Figure 11. The loads were loaded three times on every implant to find the consistency.

\section{Results}

Load are applied on the cranial and caudal parts of the implant in groups I, II, III, and IV, and the distribution of stress is indicated by the color code. Maximum and minimum values of the principal stress

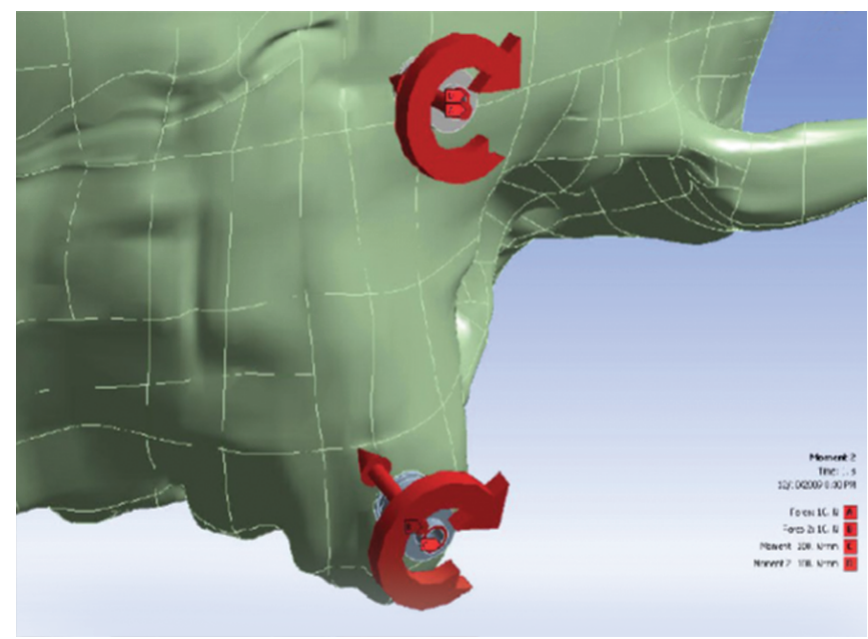

Fig. 11: Axial and moment load applied on the implant
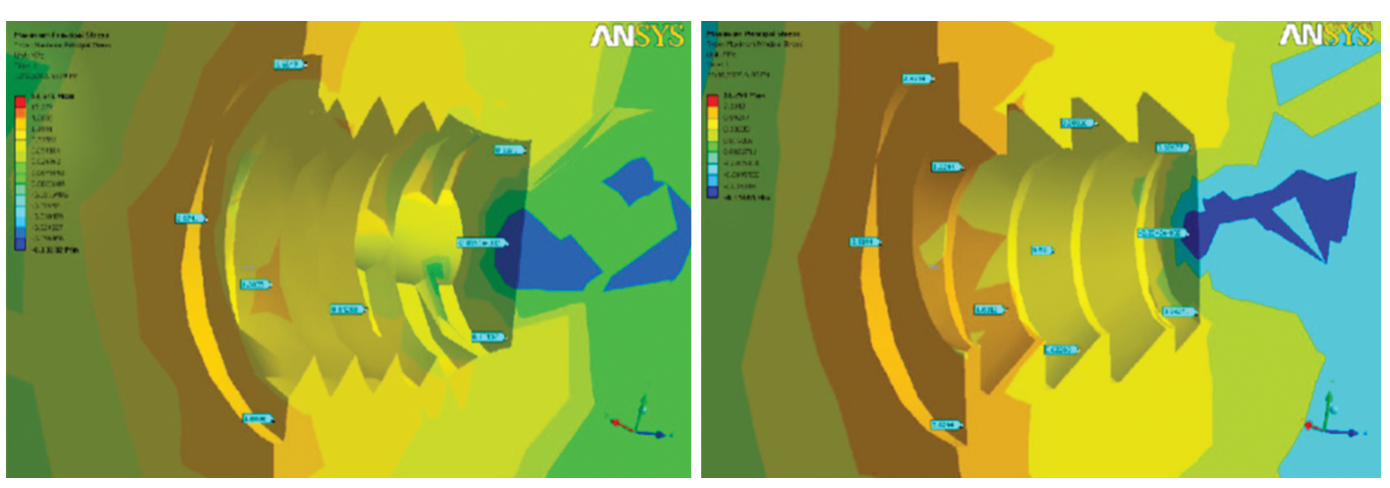

Fig. 12: Stress distribution in group IA and in group IIA
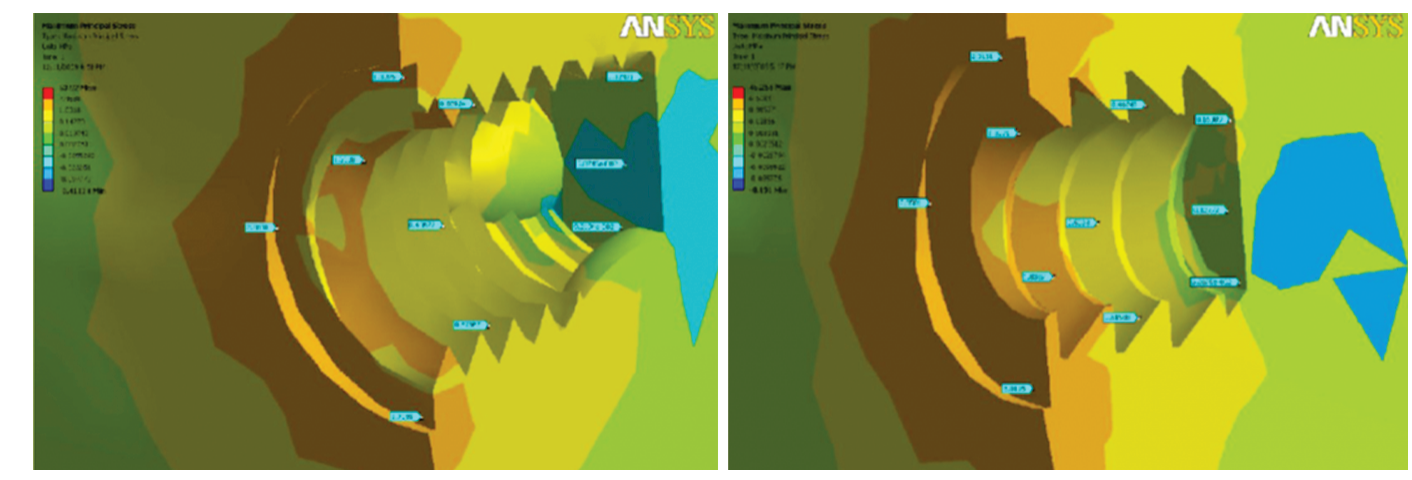

Fig. 12: Stress distribution ingroup IA and ingroup IIA is denoted by the red and blue color, respectively. Figures 12 to 14 represent the stress distribution in the implant without connection by bar, and the maximum stress concentration occurs at the flange and gets distributed to the thread, wherein in the first thread the maximum stress concentration occurs and gets dissipated progressively. Figures 15 and 16 represent stress distribution in the implant with bar connection, and the maximum stress is taken up by the bar and the distribution to the implant is very less.

Tables 3 and 4 describe the mean, standard deviation and standard error between the subgroups IA, IB, and IC vs IIA, IIB, and IIC at the various positions of the implant at the flange, middle, and the end part of the implant. The mean load over the implant without the connecting bar at the cranial portion of the implant range from 0.001 to 1.74 as shown in Table 3. The mean load over the implant without the connecting bar at the caudal portion of the implant range from -0.0045 to 0.459 shown in Table 4. The statistical significance between the groups I and II is shown in Table 5. The variance between the groups was assessed by Levene's test for the equality of variance. The difference in mean between the group was assessed by $t$ test. The same type of test was performed in groups IIIA, IIIB, IIIC vs IVA, IVB, and IVC as shown in Tables 6 to 8.

The mean stress distribution in groups IA and IIA in the flange, middle, and at the end region is (1.746 and 2.65), (0.542 and 0.547), and $(0.112$ and 0.102$)$, respectively, which clearly depicts the maximum concentration at the flange and less at the end region, groups IB and IIB and groups IC and IIC behave in the similar way. The mean stress distribution in groups IIIA and IVA in the flange, middle, and at the end region is ( 0.359 and 0.315$),(0.280$ and 0.183$)$, (0.166 and 0.185$)$, respectively, and these finding are suggestive of the decrease in stress concentration at the implant when connected by a bar. The groups IIIB and IVB and groups IIIC and IV C behave in the similar way.

Fig. 13: Stress distribution in group IB and in group IIB 

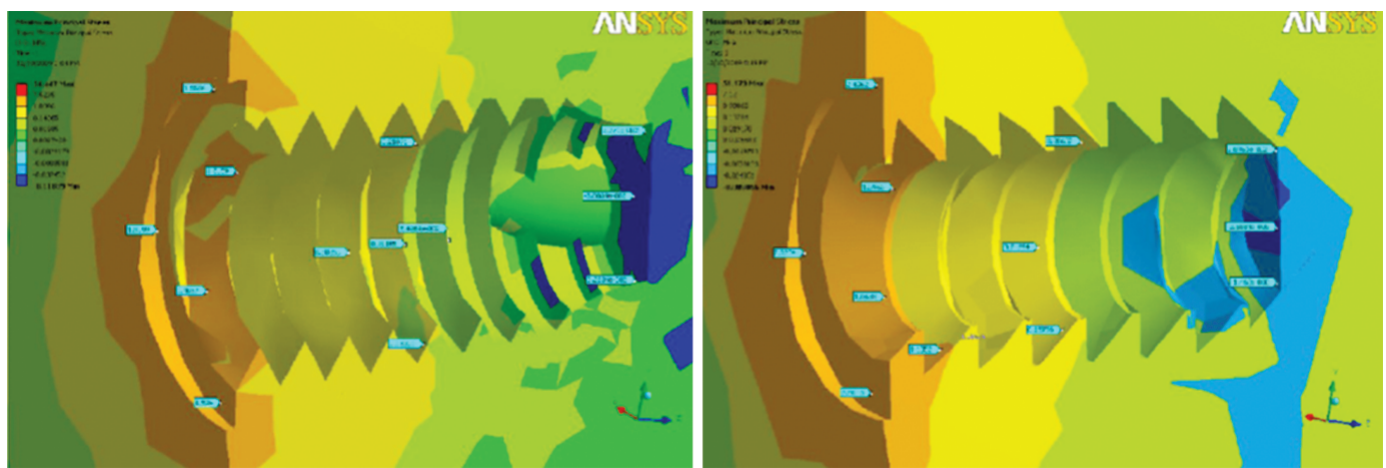

Fig. 14: Stress distribution in group IC and in group IIC
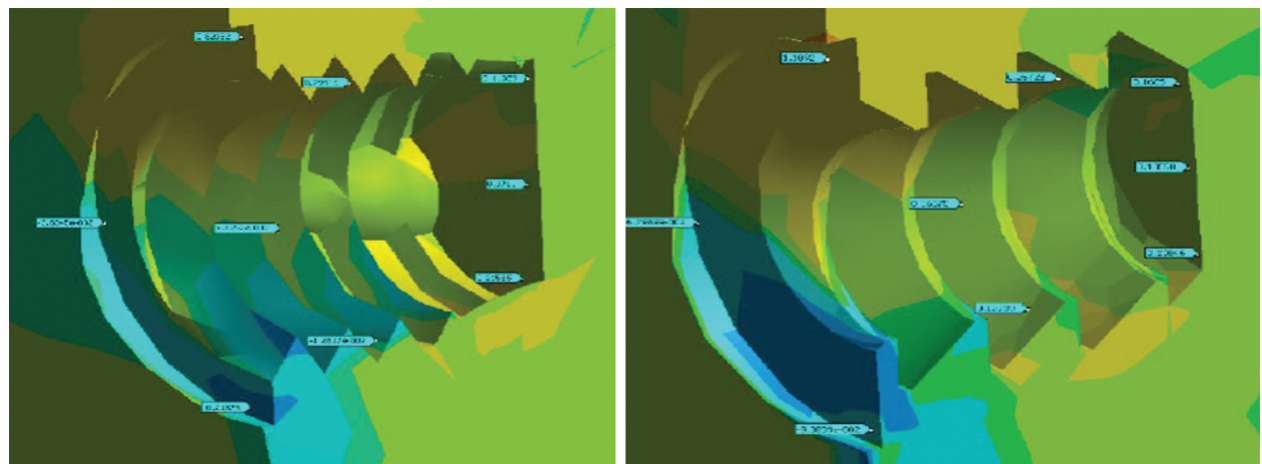

Fig. 15: Stress distribution in group IIIA and in group IVA
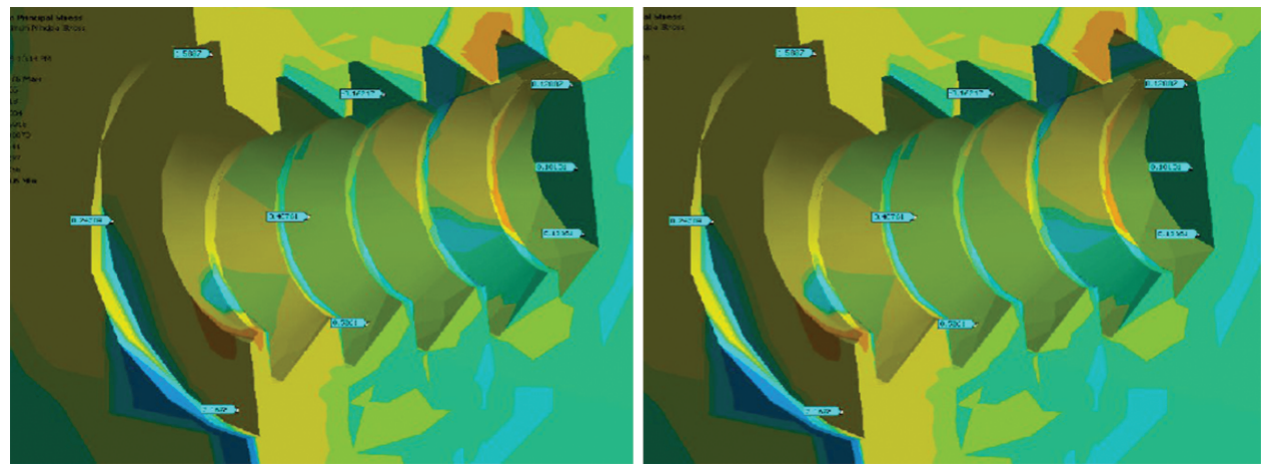

Fig. 16: Stress distribution in group IIIB and in group IVB

\section{Discussion}

The success of osseointegrated implant depends upon the mechanical loading. The way in which load from the implant is transferred to the hard tissue provides the stimulus that results in either remodeling or modeling. If the strains around the bone are beyond the physiologic range, then failure of the bone and or bone-implant interfaces occurs. ${ }^{8}$ This situation holds good both for intraoral and for extraoral implants.

Stress distributed to the implant depends upon various factors such as design of the implant, the type of bone, and the amount of force offered by the prosthesis. The design of craniofacial implant differs from that of the implant used in intraoral situation. The loading condition is completely different from that of the intraoral one, and the craniofacial implant will be loaded only during the insertion and removal of the prosthesis. Hence, a study on implant design with focus on thread shape and length is needed.
Considering these parameters a study was conducted to evaluate the stress distribution in the temporal region with craniofacial auricular implant used to retain auricular prosthesis.

Craniofacial auricular implants are commercially available in various lengths with flanges of $3 \mathrm{~mm}, 4 \mathrm{~mm}$, and $6 \mathrm{~mm}$, respectively. Commercially available craniofacial auricular implants are marketed by (1) Branemark (Noble Biocare AB, Sweden), (2) Bud (Bud industries NY), (3) IMZ (Friatec AG, Germany), ${ }^{8}$ and (4) Southern Implants (Irene, South Africa). Craniofacial auricular implant marketed by Southern implant was taken as a control group because of two reasons, namely, easy availability in India and economically feasible. The implant used for this study was V-shaped thread with the length of $3 \mathrm{~mm}$ and diameter of $3.75 \mathrm{~mm}$ was taken as control group.

The best method for analyzing the stress distribution was FEA, and it is better and widely used to study the stress distribution in the implant and around the bone. ' Lot of studies have been conducted on design of implant used in intraoral situation. Some of the studies 
Table 3: Stress distribution in the cranial part of the implant without connection by bar

\begin{tabular}{lllllll}
\hline S.no & $\begin{array}{l}\text { Position of the } \\
\text { auricularimplant }\end{array}$ & Sample & $n$ & Mean & Std. deviation & Std. error mean \\
\hline 1 & Flange & IA & 3 & 1.746200 & 0.2931157 & 0.1692304 \\
& IIA & 3 & 2.654067 & 0.3293408 & 0.1901450 \\
& Middle & IA & 3 & 0.5425800 & 0.00000000 & 0.00000000 \\
& IIA & 3 & 0.5477733 & 0.06557071 & 0.03785727 \\
& End & IA & 3 & 0.112436 & 0.1217685 & 0.0703031 \\
& Flange & IIA & 3 & 0.102379 & 0.1102356 & 0.0636445 \\
& & IB & 3 & 1.741167 & 0.4459257 & 0.2574553 \\
& Middle & IIB & 3 & 2.610300 & 0.3606281 & 0.2082087 \\
& IB & 3 & 0.6378100 & 0.21536092 & 0.12433869 \\
& End & IIB & 3 & 0.5288833 & 0.07744199 & 0.04471116 \\
& IB & 3 & 0.089083 & 0.0368810 & 0.0212933 \\
& Flange & IIB & 3 & 0.115495 & 0.0486119 & 0.0280661 \\
& IC & 3 & 1.691133 & 0.2669469 & 0.1541219 \\
& Middle & IIC & 3 & 2.470300 & 0.1358150 & 0.0784128 \\
& IC & 3 & 0.1714900 & 0.05469798 & 0.03157989 \\
& End & IIC & 3 & 0.2255900 & 0.02807100 & 0.01620680 \\
& IC & 3 & 0.010122 & 0.0355944 & 0.0205504 \\
& IIC & 3 & 0.001214 & 0.0181038 & 0.0104522 \\
\hline
\end{tabular}

Table 4: Stress distribution in the caudal part of the implant without connection by bar

\begin{tabular}{lllllll}
\hline S.no & $\begin{array}{l}\text { Position of the } \\
\text { auricular implant }\end{array}$ & Sample & $n$ & Mean & Std. deviation & Std. errormean \\
\hline 1 & Flange & IA & 3 & 1.890967 & 0.4599887 & 0.2655746 \\
& IIA & 3 & 2.556367 & 0.5153380 & 0.2975306 \\
& Middle & IA & 3 & 0.7636667 & 0.14710385 & 0.08493045 \\
& IIA & 3 & 0.6137567 & 0.09069754 & 0.05236425 \\
& End & IA & 3 & 0.119590 & 0.1309925 & 0.0756286 \\
& Flange & II & 3 & 0.108200 & 0.1141276 & 0.0658916 \\
& & IB & 3 & 2.021000 & 0.4395108 & 0.2537517 \\
& Middle & IIB & 3 & 2.770167 & 0.3212474 & 0.1854723 \\
& IB & 3 & 0.5394000 & 0.07213619 & 0.04164785 \\
& End & IIB & 3 & 0.5977767 & 0.14537860 & 0.08393437 \\
& IB & 3 & 0.105295 & 0.0749010 & 0.0432441 \\
& Flange & IIB & 3 & 0.065617 & 0.0955241 & 0.0551508 \\
& IC & 3 & 1.931667 & 0.4343503 & 0.2507722 \\
& Middle & IIC & 3 & 2.673933 & 0.3439934 & 0.1986047 \\
& IC & 3 & 0.2904100 & 0.07576001 & 0.04374006 \\
& End & IIC & 3 & 0.2624367 & 0.04549044 & 0.02626392 \\
& IC & 3 & -0.004500 & 0.0384380 & 0.0221922 \\
& IIC & 3 & -0.012342 & 0.0055108 & 0.0031816 \\
\hline
\end{tabular}

that focus on stress distribution by FEA are discussed here. The stress distribution on implant depends on the length diameter and the thread design. The influence of implant length and diameter and thread design on stress distribution in intraoral using FEA was well evaluated by numerical and 3D FEA.

Finite element studies on craniofacial implant were limited, and little work has been reported on the differences related to design, loading, and bone configurations of implants used in craniofacial regions. Literature review of FEA in craniofacial implant goes back to 1997 done by Victor del valle et al., after which this area is less explored. He evaluated the stress distribution that occurs in the region surrounding craniofacial osseointegrated implants using FEA. ${ }^{8}$ This study was about the stress distribution in the craniofacial implant with flange and without flange, and the importance of thread shape and the length of the implant on stress distribution have not been studied. Hence, it was decided to conduct a study on stress distribution in the implants and the bone surrounding craniofacial auricular implants with different implant thread shapes, having varying lengths and constant diameter using FEA. 


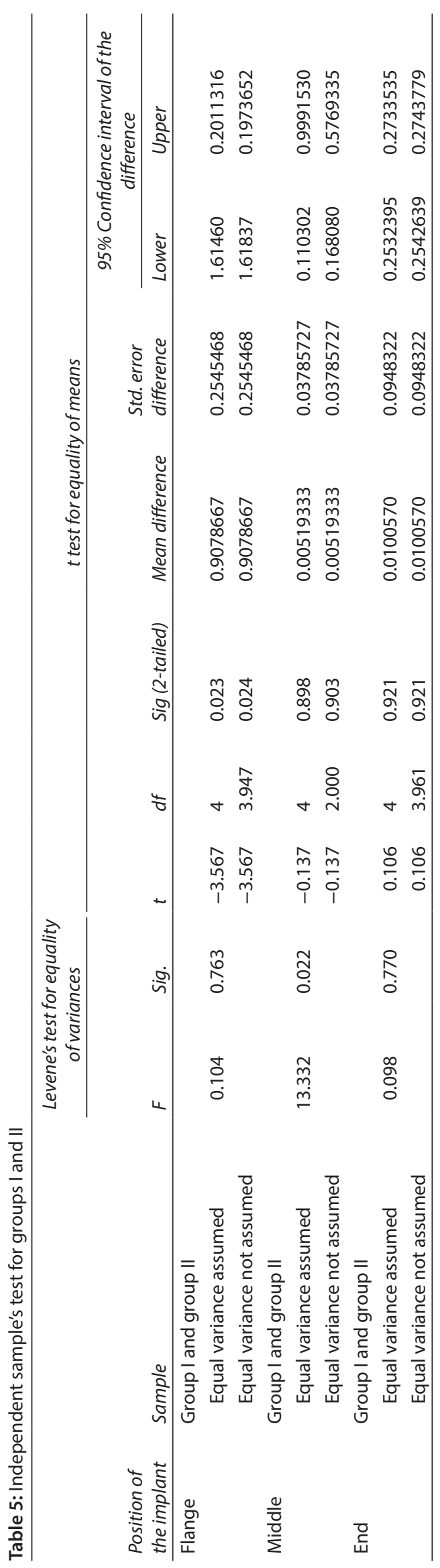

Shape of the thread is considered to be an important factor in the long-term load transfer to the surrounding bone. Under axial load to an implant-bone interface buttress- or square-shaped thread would transmit compressive force to the bone. The stress distribution of V-shaped and reverse buttress is similar. ${ }^{9}$

The V-shaped thread is the most common commercially available thread design for implants used in intraoral and extraoral retained prostheses. Square-shaped thread is able to transmit high compressive and low shear stress to the bone, and it is unsuitable for smaller implants. ${ }^{4}$ Buttress is considered for supporting the maxillofacial prosthesis of which the reverse buttress is more favorable because it is able to resist the pull out and push out forces; ${ }^{4}$ and taking this into consideration, the reverse buttress is taken as the thread for the indigenous implant.

The most important step in the FEA is the method by which the bone model is generated, the easiest method is the generation of numerical model. In the previous studies on craniofacial implants, numerical model was generated where the bone was considered to be isotropic and homogenous with the character of cortical bone and by imparting the Poison ratio, Young modulus of elasticity and density of the material. ${ }^{8}$ In the present study, 3D model was generated to assess the stress distribution. The method of scanning to produce the $3 \mathrm{D}$ cloud point to produce a solid model of the temporal bone region is considered superior when compared to the numerical model because scanning method is considered to be precise and accurate.

To measure the thread profile of the implant, the optical comparator was used. For measuring the thread profile of an implant of $3.75 \mathrm{~mm}$ diameter, a magnification level of $10 \times$ was sufficient. The optical comparator had a magnification range of up to $100 \times$. Therefore, the thread profile of the implant was accurately obtained at a magnification of $100 \times$ using the optical comparator.

In finite element technique, the programmed software ANSYS was used in the present study to conduct the $3 D$ analysis, and this is considered to be one of the most accurate methods for stress analysis. The results of which are presented in color graph format to know the stress and strain pattern development.

Studies were done on biomechanical model of ear case, to predict the loadings on two implants when a test load of magnitude $10 \mathrm{~N}$ is applied in at a particular point on the framework. Consideration was made in a horizontal load in the plane of the prosthetic bar, perpendicular to the long axes of the two implants in the bone; $10 \mathrm{~N}$ was found to be the nominal test load. No data are available on the actual forces on the type of prosthesis in vivo. ${ }^{10}$ In the present study, similar to previous studies two loading conditions, one vertical load of $10 \mathrm{~N}$ and second a moment of $100 \mathrm{Nmm}$, were applied to the center of the craniofacial auricular implants ${ }^{8}$ individually and to the center of gold bar which connects the two implants.

The buttress-shaped thread design has known advantages of providing more bone-to-implant contact and reduction in abutment stresses and strain. Therefore, more contact area provides increased initial stability and reduces the stresses. The stress distribution in groups I and II (V-shaped thread) is better when compared to groups III and IV (reverse buttress) which is contradictory to the above statement.

\section{Conclusion}

The stress distribution in the implants used to retain the auricular prosthesis is decided by the presence of the flange, and the 
Table 6: Stress distribution in the cranial part of the implant with bar

\begin{tabular}{lllllll}
\hline \multicolumn{2}{c}{$\begin{array}{l}\text { Position of the } \\
\text { S.no }\end{array}$} & Sample & $n$ & Mean & Std. deviation & Std. error mean \\
\hline 1 & Flange & IIIA & 3 & 0.359290 & 0.4097536 & 0.2365713 \\
& IVA & 3 & 0.315833 & 0.6871977 & 0.3967538 \\
& Middle & IIIA & 3 & 0.2809967 & 0.44623901 & 0.25763621 \\
& IVA & 3 & 0.1838067 & 0.06660368 & 0.03845365 \\
& End & IIIA & 3 & 0.166913 & 0.0511027 & 0.0295042 \\
& Flange & IVA & 3 & 0.185000 & 0.0235160 & 0.0135769 \\
& & IIIB & 3 & 0.172990 & 0.5377368 & 0.3104625 \\
& Middle & IVB & 3 & 1.332863 & 0.9880177 & 0.5704323 \\
& IIIB & 3 & 0.2587167 & 0.4413136 & 0.25699671 \\
& End & IVB & 3 & 0.2571800 & 0.36796846 & 0.21244669 \\
& IIIB & 3 & 0.181303 & 0.1341366 & 0.0774438 \\
& Flange & IVB & 3 & 0.118333 & 0.0165630 & 0.0095627 \\
& IIIC & 3 & 0.339657 & 0.9114198 & 0.5262085 \\
& Middle & IVC & 3 & 0.344977 & 0.4596799 & 0.2653963 \\
& IIIC & 3 & 0.6652667 & 1.12646259 & 0.65036348 \\
& End & IVC & 3 & 0.0526200 & 0.11866645 & 0.06851210 \\
& IIIC & 3 & 0.158000 & 0.0470319 & 0.0271539 \\
& & IVC & 3 & 0.053267 & 0.0263299 & 0.0152016 \\
\hline
\end{tabular}

Table 7: Stress distribution in the caudal part of the implant with bar

\begin{tabular}{|c|c|c|c|c|c|c|}
\hline S. no & $\begin{array}{l}\text { Position of the } \\
\text { auricular implant }\end{array}$ & Sample & $n$ & Mean & Std. deviation & Std. error mean \\
\hline \multirow[t]{6}{*}{1} & Flange & IIIA & 3 & 0.400867 & 0.4953286 & 0.2859781 \\
\hline & & IVA & 3 & 0.276190 & 0.6364660 & 0.3674638 \\
\hline & Middle & IIIA & 3 & 0.3698300 & 0.50545122 & 0.29182240 \\
\hline & & IVA & 3 & 0.2004067 & 0.06501010 & 0.03493552 \\
\hline & End & IIIA & 3 & 0.160700 & 0.0476211 & 0.0274940 \\
\hline & & IVA & 3 & 0.189333 & 0.0732006 & 0.0422624 \\
\hline \multirow[t]{6}{*}{2} & Flange & IIIB & 3 & 0.389910 & 0.5215614 & 0.3011236 \\
\hline & & IVB & 3 & 6.195533 & 4.4813867 & 2.5873298 \\
\hline & Middle & IIIB & 3 & 0.3737600 & 0.5275725 & 0.30456800 \\
\hline & & IVB & 3 & 0.3067467 & 0.80612606 & 0.46541710 \\
\hline & End & IIIB & 3 & 0.168050 & 0.1230164 & 0.0710235 \\
\hline & & IVB & 3 & 0.218400 & 0.1205798 & 0.0696168 \\
\hline \multirow[t]{6}{*}{3} & Flange & IIIC & 3 & 0.136780 & 0.264180 & 0.034679 \\
\hline & & IVC & 3 & 0.326890 & 0.763410 & 0.087632 \\
\hline & Middle & IIIC & 3 & 0.41280 & 0.68432 & 0.08321 \\
\hline & & IVC & 3 & 0.76543 & 0.32671 & 0.76532 \\
\hline & 'End & IIIC & 3 & 0.87654 & 0.56432 & 0.35672 \\
\hline & & IVC & 3 & 0.54390 & 0.53217 & 0.89654 \\
\hline
\end{tabular}

type of thread used does not have much influence. The type of attachment used to retain the prosthesis also influences the nature of stress; magnetic attachment has less stress when compared to bar and clip attachment. The implant in the temporal bone are subjected to loading during the insertion and removal of the prosthesis. The type of force exerted is pull out and push out of force. Bar and clip retained ear prosthesis exert force when compared to the magnet. Further studies are suggested with the following focus: primary stability of implant, and pull out and push out force in V-shaped and reverse buttress design will help us to decide the type of thread that is clinically and biomechanically better.

\section{Acknowledgments}

The authors like to thank Mr.Ravichandran for helping in making indigenous implant and also to the Central Institute of Plastic 


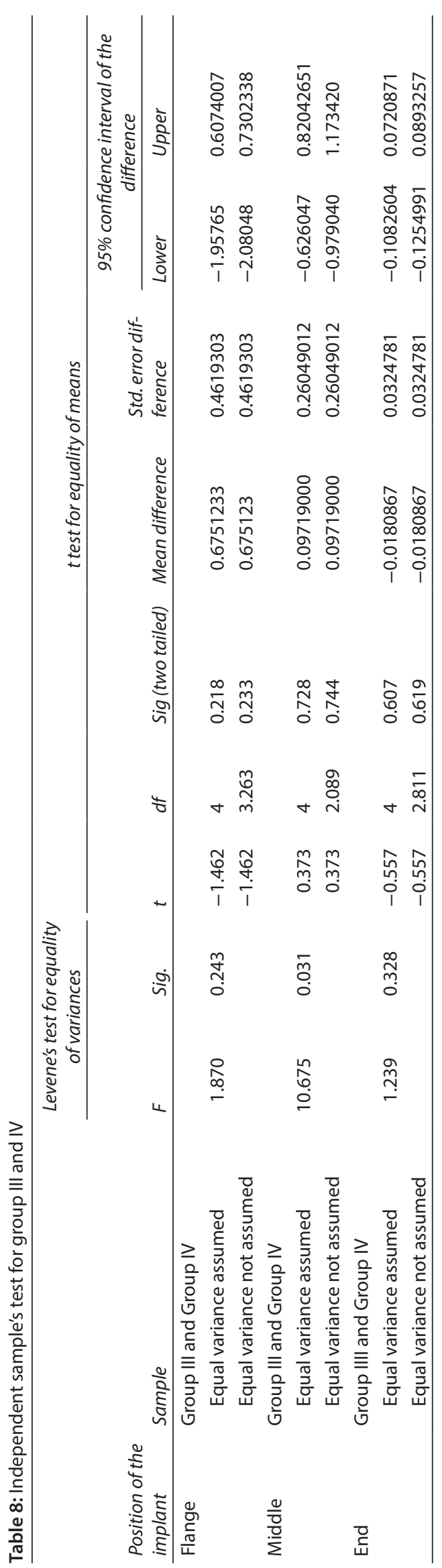

Engineering Technology for spending time in the finite element analysis.

\section{References}

1. Akagawa Y, Sato Y. A mimic osseointegrated implant model for threedimensional finite element analysis. J Oral Rehabil 2003;30(1):41-45. DOI: 10.1046/j.1365-2842.2003.01002.x.

2. Wolfaardt J. International prespective on treatment outcomes in Per-Ingvar Branemark Tolman DE. Osseointegration in Craniofacial Reconstruction. Chicago: Quintessence; 1998. p. 68.

3. Brunski JB, Skalak. R. Biomechanical considerations for craniofacial implants in Per -Ingvar Branemark Tolman DE. Osseointegration in Craniofacial Reconstruction. Chicago: Quintessence; 1998. p. 24.

4. Lovely M, Munirathnam Naidu E. Design and development of an implant system for auricular prosthesis. Trends Biomater Artif Organs 2010;24:11-18.

5. Higuchi KW. Surgical principles of osseointegration in PerIngvar Branemark Tolman DE. Osseointegration in Craniofacial Reconstruction. Chicago: Quintessence; 1998. p. 113.

6. Southern implants Cranio Facial Reconstruction Manual CAT-203602(C344), p. 2.

7. de Olivera MF. Auricular prosthesis in Per-Ingvar Branemark Tolman DE. Osseointegration in Craniofacial Reconstruction. Chicago: Quintessence; 1998. p. 214.

8. de Valle V, Faulkner G. Craniofacial osseointegrated implant-induced strain distribution: A numerical study. J Oral Maxillofac Implants 1997;12:200-210.

9. Misch C, Todd Strong J. Scientific rationale for dental implant design Misch CE. Contemporary implant Dentistry. 3rd ed., Mosby; 2008. p. 205.

10. Brunski JB, Skalak R. Biomechanical considerations for craniofacial implants in Per-Ingvar Branemark Tolman DE. Osseointegration in Craniofacial Reconstruction. Chicago: Quintessence; 1998. p. 30. 